\title{
APPROPRIATENESS OR EXPECTED RETURNS? ORGANIZATIONAL REPRESENTATIONS OF CORPORATE ENVIRONMENTALISM
}

\author{
DÉBORAH PHILIPPE \\ HEC PARIS \\ 1 rue de la Libération - 78351 Jouy-en-Josas Cedex, France
}

\begin{abstract}
This paper explores how organizations build representations of their corporate environmentalism in their annual reports. From the content analysis of the reports of 7 Canadian firms in the resource industry over 20 years, I identify the emergence of three organizational stories describing the relationship of organizations with the natural environment.
\end{abstract}

\section{INTRODUCTION}

Building on Meyer and Rowan's (1977) seminal paper, many scholars have investigated the processes by which organizations strive to adapt to institutional pressures. A central claim of institutional theory is that organizations sharing the same environment and confronted with the same institutional pressures will adopt similar practices and therefore become isomorphic with each other (e.g., DiMaggio \& Powell, 1983; Townley, 1997). The institutional perspective explains the organizations' conformity to institutional pressures as mainly driven by legitimacy reasons (DiMaggio \& Powell, 1983; Oliver, 1991).

While scholars have made significant advances in identifying how organizations adapt to their environment through the isomorphic adoption of highly institutionalized practices, the existence of variations in the adoption process has failed to receive a similar level of attention. Although recent works have started exploring how differences in key elements of the institutional environment (e.g., legal systems or culture) could lead to variations in the adoption of organizational practices (e.g., Gooderham, Nordhaug \& Ringdal, 1999; Kostova, 1999; Kostova \& Roth, 2002), there has been little attempt in the institutional literature to explore the role of meanings and values in shaping the adoption of highly institutionalized practices. The institutional perspective has not considered how the "inside" of the organization could impact the way institutional pressures are interpreted and rendered meaningful by organizations. The aim of this study is thus to reconnect institutional research with what occurs inside the organization (i.e., how institutional pressures are internalized) and see how the infusion of meanings and values can produce different interpretations of institutional pressures.

The empirical case on which I base this paper is a study of corporate environmentalism, defined as "the recognition and integration of environmental concerns into a firm's decisionmaking process" (Banerjee, 2002: 177). In the last two decades, the management of the natural environment has become a crucial issue facing organizations (Bansal, 2005). Environmental communication plays a crucial part in the organizations' environmental management. To be effective, the management of the natural environment indeed requires communicating on the organization's environmental practices. Corporate environmentalism thus proves particularly interesting to focus on because it is intrinsically related to the production of organizational texts useful to conduct empirical studies (Deephouse \& Carter, 2005; Phillips, Lawrence \& Hardy, 2004). In this paper, I am specifically interested in understanding how organizations frame their 
relationship with the natural environment within their corporate communication and how they build representations of their corporate environmentalism.

\section{THEORETICAL BACKGROUND}

Organizational practices reflect the established way of conducting organizational functions. They are shaped by the institutional context in which they are enacted (Meyer \& Rowan, 1977) and they are adopted by organizations through coercive, normative and mimetic processes (DiMaggio \& Powell, 1983). Tolbert and Zucker (1996) and Kostova and Roth (2002) suggest that the adoption of an organizational practice can be conceptualized at two levels - (1) the implementation, which corresponds to the formal adoption of a specific pattern of behavior and (2) the internalization, which corresponds to the values and meanings that are infused in the practice by the organization (Selznick, 1957). In this study, I focus on the latter dimension of the adoption process. This internalization dimension is important because it facilitates both the initial adoption of the practice and its persistence over time (Kostova, 1999; Kostova \& Roth, 2002; Tolbert \& Zucker, 1996). However, it has so far been neglected in the institutional literature.

The empirical case on which I base this paper is a study of corporate environmentalism. Increases in societal concerns for the degradation of the natural environment have contributed to the emergence of social norms on environmental issues (Banerjee, 2001, 2002; Hoffman, 1999). Because firms are accountable for the impacts of their activities on the natural environment, they are expected to integrate environmentally friendly practices in their activities. Expectations of conformity have dramatically increased in the field of environmental management and the natural environment is increasingly being drawn into organizational discourses (e.g., Milne, Tregidga, \& Walton, 2008; Newton, 2005; Prasad \& Elmes, 2005). In this paper, I am interested in understanding how institutional pressures regarding environmental friendliness are interpreted by organizations and subsequently framed in their corporate communication.

How organizations frame their discourse about the natural environment is "both integral to environmental management itself and a critical aspect of business sustainability" (Livesey, 2002: 83). Environmental discourses can be understood as attempts to "shape and manage the institutional field of which they are part" (Hardy \& Phillips, 1999: 1). According to Driver (2006), CSR is not a question of whether organizations are/should be ethical (i.e., adopt an "other-centred" paradigm vs. a "self-centred" one) or whether they are/should be responsible for the wider community, but whether or not they understand themselves to be so. How organizations build representations of their relationships with the natural environment is thus crucial not only to the production of meaning (Milne et al., 2008), but also to the internalization of institutional pressures relative to the adoption of environmentally-friendly practices. We can investigate these representations which participate to the construction and enactment of the organizational self through organizational discourses (Driver, 2006; Hardy, 2004) because the organizational self is indeed "continuously constructed, de-constructed, and re-constructed in various narratives" (Driver, 2006: 342). These narratives thus reflect the systems of meaning and values of the organizations. Exploring these narratives should enable us to understand the interpretative schemes that organizations develop to guide their perceptions and actions (Ranson, Hinings \& Greenwood, 1980). These "schemata of interpretation" (Goffman, 1974: 21), generally referred to as frames, enable actors to reduce socio-cultural complexity and render events meaningful. 
Here, I suggest that when confronted with strong external pressures from their institutional environment to adopt environmentally friendly practices, organizations will infuse them with different meanings and thus frame them differently in their corporate communication. Even if we observe homogeneity at the implementation level, there should be heterogeneity at the internalization level, that is, organizations will produce different discursive representations of their relationships with the natural environment. To examine these variations in the way the social norm for corporate environmentalism is internalized and rendered meaningful by organizations, I draw on March (1994) and March and Olsen's (1998) logics of consequences and appropriateness. To account for the basic logic of human behavior as well as the way this behavior is interpreted, the authors identify two logics. On one side, action is driven by a logic of anticipated consequences, while on the other it is driven by a logic of appropriateness and senses of values. The consequential logic suggests that actions are driven by expectations of returns.

The logic of consequences considers decisions as "based on an evaluation of alternatives in terms of their consequences for preferences" (March, 1994: 57). In contrast, the logic of appropriateness suggests that action involves doing what is essential to one's particular values and beliefs and/or what is in accordance with the rules and practices that are socially constructed and taken-for-granted. These two logics thus specify different modes of action for actors.

\section{METHODS}

\section{Research Setting}

I examine the environmental communication of a set of Canadian firms belonging to the resource industry. To date, the sample comprises 7 firms operating in 3 different sectors: 1) forestry, paper and forest products; 2) oil \& gas; and 3) mining. I selected an industry specific sample on the basis of the following considerations: First, the industry focus allows me to ensure contextual validity of data. Practices associated with environmental responsibility are indeed often context-specific (Bansal, 2005). Second, this is an industry facing major environmental exposures and thus likely to attract the attention of different market participants (e.g., media). Prior research indicates that organizations belonging to visibly polluting sectors such as the resource industry are reactive to environmental issues (Bansal, 2005; Bansal \& Roth, 2000). Eventually, this is an industry that has undergone important transformation in the last two decades (Bansal, 2005).

\section{Data and Procedures}

The main source of data consists in the annual reports of these 7 organizations from 1986 to 2007. Following Tolbert and Zucker (1983) and Bansal (2005), a content analysis of the annual reports was carried out for 8 years - 1986, 1989, 1992, 1995, 1998, 2001, 2004 and 2007. The earliest year of the analysis, 1986, was chosen because it seems that awareness of sustainable development was very limited prior to 1987 - the year that sustainable development was popularized by the publication of the Brundtland Commission report and by the Montreal Protocol. The final year, 2007, is the last year for which organizations released an annual report during the data collection period.

The first step was to retrieve the annual reports for all the firms in the sample. For each firms except one (due to missing data for the years 2004 and 2007), I collected 8 reports. The 
second step consisted in importing the content of the annual reports into the software analysis tool Nvivo 7. I only imported the content of the narrative sections of the annual reports as I was not interested in the standardized audited discourses present in the Managerial Discussion and Analysis (MD\&A) and financial sections of the reports. The third step consisted in undertaking a content analysis (Krippendorff, 1980; Weber, 1985) of annual reports to assess whether firms were using different frames to talk about their relationships with the natural environment. The categorization of the frames was built inductively via the discourse content-analysis.

\section{Chronotopic Analyses}

The construction of meaning through a narrative requires a governing plot that will give the narrative an overarching coherence and situate it in time and space (Boje, 2001;

Czasrniawska, 2004). Literary theory suggests that the chronotope - the spatio-temporal matrix which governs the base condition of all narratives (Bakhtin, 1981) - builds the whole discourse structure. According to Bakhtin (1981: 250), the chronotope is the place "where the knots of narrative are tied and untied. It can be said, without qualification, that to them belongs the meaning that shapes narrative... spatial and temporal indicators are fused into one concrete whole. This intersection of axes and fusion of indicators characterizes the chronotope". In the context of this study, both the temporal and spatial dimensions seem particularly interesting to explore because they enable us to understand how corporate environmentalism is embedded in the space-time world of organizations. A large part of my content analyses was thus focused on chronotopic analyses - the exploration of the temporal and spatial matrixes developed in the organizations' communication. Specifically, I identified variations in the organizations' spatiotemporal orientations, relative to their continuous or discontinuous representation of space and time.

Temporal continuity refers to a mechanism binding successive events and temporal discontinuity to a fragmented sequential representation of events. At the interorganizational level, spatial continuity refers to a representation of the organization as connected with the wider community and spatial discontinuity as a fragmented representation of the community where actors are unrelated with one another. At the intra-organizational level, spatial continuity refers to a representation of corporate environmentalism as embedded within the organization and spatial discontinuity as a representation of corporate environmentalism as peripheral to the organization's core activities.

\section{RESULTS}

\section{Three Competing Logics}

March (1994) and March and Olsen (1998) emphasize the existence of two logics appropriateness and consequences (or expected returns). Although most of the research using these logics overlooks the dual dimension of the logic appropriateness (doing what is essential to one's particular values and mission or what is considered socially desirable), I argue that these two dimensions should be considered as separate because they involve two different behavioral mechanisms. The data explored in the study clearly supports the idea of a dual dimension of the logic of appropriateness - an endogenous dimension and an exogenous one. In the first case, the appropriateness of actions is assessed with regards to the organization's own behavioral rules 
(i.e., what it thinks it should do considering its mission and the values it professes). In the second case, the appropriateness of actions is assessed with regards to external behavioral rules (i.e., what others think the organization should do). This observation leads me to suggest that organizations have actually recourse to three (and not two) different logics to frame their environmental communication.

\section{The Spatiotemporal (Dis)continuity Framework and the Emergence of Three Stories}

The data studied here indicates the existence of three different chronotopes - three different spatiotemporal framings of the organization's environmental behavior. By connecting these three chronotopes with the three logics used by organizations, I see three stories emerging on the relationships between the organization and the natural environment: a profit-seeking story; a legitimacy-enhancement story; and a value-driven story.

In the profit-seeking story, corporate environmentalism is represented as valuable to the organization because of its economic advantages. The story is framed through a logic of consequences, where corporate environmental behavior is motivated by the search of profit. As corporate environmentalism has never been an important concern for the organization, only its economic aspect matters. Consequently, the addition of corporate environmentalism is dictated by the laws of market. It remains peripheral within the organization and does not entail changes in the organizational self. Chronotopic analyses thus indicate both temporal and spatial discontinuity, that is, no embeddedness of corporate environmentalism within the spatiotemporal world of the organization.

In the legitimacy-enhancement story, corporate environmentalism is represented as valuable to the organization because of its legitimacy advantages. The story is framed through an exogenous logic of appropriateness, where corporate environmentalism is motivated by the conformity to external social norms and rules. Corporate environmentalism has not always been part of the organization's activities but given the institutional pressures towards incorporating environmentally-friendly practices, it is given increasing importance in the organization's strategic decision-making process. The organization is striving to incorporate environmental reflections in its daily activities and this entails changes in its organizational self. However, the organization is also concerned about maintaining the coherence and stability of its organizational self. Temporal continuity provides a useful means of resolving this tension. By reconnecting old and new elements of the organizational self in a temporal continuum, the organization can build a representation of temporal continuity. The internalization of the external pressures allows the organization to give sense to corporate environmentalism with regards to its own history. However, at the spatial level, it is more difficult for the organization to incorporate environmental reflections in its core processes. It also takes time to build relationships with the wider community when an organization is not used of working as a field player and representing itself as such. Chronotopic analyses thus indicate strong emphasis on temporal continuity but less on spatial continuity. This means partial embeddedness of corporate environmentalism within the spatiotemporal world of the organization.

In the value-driven story, corporate environmentalism is represented as valuable to the organization because it echoes the organization's core values. The story is framed through an endogenous logic of appropriateness, where corporate environmentalism is motivated by the organization's intrinsic values and mission. Corporate environmentalism has always been part of the organization's activities and mission and its importance is maintained or strengthened by 
institutional pressures. Consequently, there is no change is the organizational self as the same values and practices are reasserted. Chronotopic analyses thus indicate temporal and spatial continuity, that is, complete embeddedness of corporate environmentalism within the spatiotemporal world of the organization.

\section{DISCUSSION AND CONCLUSION}

According to Hazan (1984), actors are constantly trying to construct meaning by reconstructing (restructuring) the story of their activities. Such a phenomenon is particularly interesting to explore in a context where organizations are facing strong institutional pressures to incorporate changes in their organizational practices but are at the same time trying to create meaningful stories and maintain a coherent organizational self over time. In this study, I suggest that the emphasis laid on temporal continuity enables organizations to smooth the perceived impact of change, by building a discursive bridge (gradual transition vs. rupture) between the new organizational self and the former one, as successive events are presented to audiences as temporally interconnected. In turn, this temporal interconnectedness in the organization's former and new practices strengthens the causality links between organizational events and thus legitimates the organization's actions thanks to their coherence and stability in time. Similarly, the emphasis laid on spatial continuity at the interorganizational level enables the organization to present itself as interconnected with its stakeholders and thus legitimate its actions through the involvement and endorsement of other field players. At the intra-organizational level, it enables the organization to present itself as an entity where processes and values are interconnected.

This study contributes to an interpretive perspective on organizational change which suggests that the process of change (e.g., the adoption of a new practice) is accompanied by a substantial amount of cognition and interpretation (Isabella, 1990). Through its focus on the internalization dimension of the adoption of an organizational practice, it helps to reconnect institutional research with what occurs inside the organization (i.e., how institutional pressures are internalized) and see how the infusion of meanings and values can produce different interpretations of institutional pressures.

This research also contributes to the literature on environmental communication in two ways. First it offers insights on a new approach to environmental discourse analysis: the use of chronotopic analysis to understand the organizations' representations of their relationships with the natural environment. The spatiotemporal framework that emerged from the content analysis represents a way to understand if and how organizations internalize and incorporate institutional requirements in their organizational self and how they manage to give sense to corporate environmentalism with regards to their own history. Second, it contributes to this literature by emphasizing the dual dimension of the logic of appropriateness, where actions can be driven by a particular conception of the self or by what is in accordance with the rules and practices that are socially constructed. This duality is particularly relevant in the context of corporate environmentalism, where the adoption of environmentally-friendly practices can be driven by endogenous or exogenous reasons.

\section{REFERENCES AVAILABLE FROM THE AUTHOR}


Copyright of Academy of Management Proceedings is the property of Academy of Management and its content may not be copied or emailed to multiple sites or posted to a listserv without the copyright holder's express written permission. However, users may print, download, or email articles for individual use. 
Copyright of Academy of Management Annual Meeting Proceedings is the property of Academy of Management and its content may not be copied or emailed to multiple sites or posted to a listserv without the copyright holder's express written permission. However, users may print, download, or email articles for individual use. 